\title{
Arctic Sea Ice Retreat in 2007 Follows Thinning Trend
}

\author{
R. W. Lindsay, J. Zhang, A. Schweiger, M. Steele, and H. Stern \\ Polar Science Center, Applied Physics Laboratory, University of Washington, Seattle, Washington
}

(Manuscript received 11 March 2008, in final form 9 June 2008)

\begin{abstract}
The minimum of Arctic sea ice extent in the summer of 2007 was unprecedented in the historical record. A coupled ice-ocean model is used to determine the state of the ice and ocean over the past $29 \mathrm{yr}$ to investigate the causes of this ice extent minimum within a historical perspective. It is found that even though the 2007 ice extent was strongly anomalous, the loss in total ice mass was not. Rather, the 2007 ice mass loss is largely consistent with a steady decrease in ice thickness that began in 1987. Since then, the simulated mean September ice thickness within the Arctic Ocean has declined from 3.7 to $2.6 \mathrm{~m}$ at a rate of $-0.57 \mathrm{~m}$ decade $^{-1}$. Both the area coverage of thin ice at the beginning of the melt season and the total volume of ice lost in the summer have been steadily increasing. The combined impact of these two trends caused a large reduction in the September mean ice concentration in the Arctic Ocean. This created conditions during the summer of 2007 that allowed persistent winds to push the remaining ice from the Pacific side to the Atlantic side of the basin and more than usual into the Greenland Sea. This exposed large areas of open water, resulting in the record ice extent anomaly.
\end{abstract}

\section{Introduction}

Arctic sea ice retreated dramatically in the summer of 2007, shattering the previous record low ice extent set in 2005 by $23 \%$ (Stroeve et al. 2008; Comiso et al. 2008). Figure 1 shows the extent of the Arctic sea ice each September (the month of minimum extent) since the beginning of the satellite data record in 1979. The extent in 2007 falls 4 standard deviations of the residuals $(4 \sigma)$ below the downward linear trend for 19792006. What caused this precipitous drop?

The monthly average extent of Arctic sea ice has been declining in every season and every region since the beginning of the satellite record (Meier et al. 2007; Parkinson and Cavalieri 2008). The decline of perennial sea ice has been faster than the decline of the ice cover as a whole (Comiso 2002), implying a shift toward less multiyear ice and more first-year ice and thus a thinner ice pack (Maslanik et al. 2007).

The anomalous sea ice retreat in the summer of 2007 occurred mainly on the Pacific side of the Arctic basin. Kwok (2008) used satellite data to calculate the areal advection of sea ice from the Pacific to the Atlantic sector of the basin during the summers of 2003-07 using

Corresponding author address: Ron Lindsay, Polar Science Center, 1013 NE 40th St., Seattle, WA 98105.

E-mail: lindsay@apl.washington.edu ice motion derived from passive microwave measurements. The largest flux $\left(0.48 \times 10^{6} \mathrm{~km}^{2}\right)$ occurred in the summer of 2007 , accounting for $15 \%$ of the total ice retreat in the Pacific sector, the balance being lost to melt. Persistently high atmospheric surface pressure over the Beaufort Sea and low pressure over the Laptev Sea drove southerly winds from eastern Siberia that brought warm air to the Pacific sector and pushed the ice northward (Maslanik et al. 2007).

The motion of sea ice is mainly wind driven. The anticyclonic Beaufort Gyre recirculates ice in the western Arctic, allowing it to become older and hence thicker, while the Transpolar Drift Stream advects ice across the basin and out through Fram Strait. Rigor et al. (2002) describe how high Arctic Oscillation (AO) conditions from 1989 until about 1995 flushed large amounts of the older, thicker ice out of the basin. Lindsay and Zhang (2005) call this episode of high AO years the trigger that propelled sea ice into the current regime of increasing amounts of summer open water, solar heat absorption, and reduced winter ice growth. This results in thinner first-year ice that is more likely to melt completely away during the subsequent summer.

What special factors in 2007 led to the precipitous decrease in summer ice extent? Was a critical threshold in the ice-ocean system passed or was it simply unusual weather? Was the state of the ice-ocean system at the beginning of the year the most important factor or were 


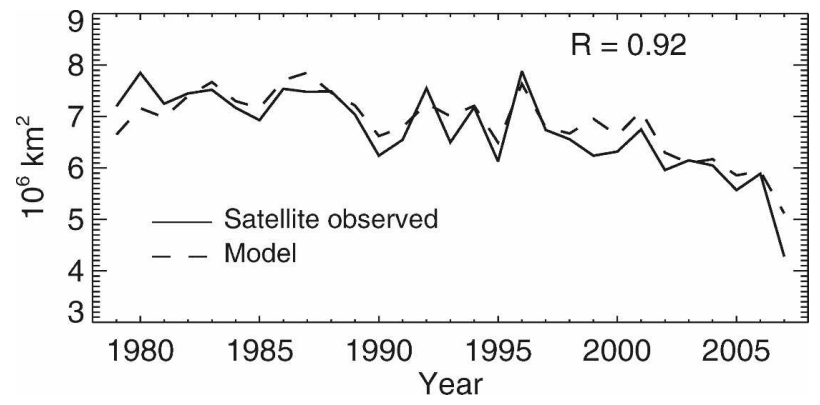

FIG. 1. Modeled and satellite-observed ice extent for the entire Arctic in September. The observed extent is from the Special Sensor Microwave Imager (SSM/I) NASA team ice concentration dataset (Meier et al. 2006).

highly anomalous winds or temperatures in 2007 solely responsible for the decline? Our objective in this paper is to quantify the importance of each factor and to use the events of 2007 to further our understanding of how the ice-ocean system is evolving in the modern epoch of a warming Arctic.

The analysis of Zhang et al. (2008) gives a month-bymonth interpretation of the events of 2007. They show that there was increased ice mass advection from the Pacific sector to the Atlantic sector of the Arctic Ocean and into the Greenland Sea, caused primarily by anomalous winds in July, August, and September, and that this increase in advective loss increased the openwater area and set the stage for increased absorption of solar flux and consequently increased melt of ice volume. The present analysis provides a longer-term perspective and puts the events of 2007 into the context of a changing ice cover over the period 1987-2006. We also expand our analysis and include ice mass and ice area budgets to help further illuminate the mechanisms involved in the sea ice anomaly of 2007.

The paper is organized as follows: section 2 introduces the model, the forcing fields, and the validation studies. Section 3 presents an analysis of the changes in the ice mass, area, and extent; the ice thickness distribution; and the open-water formation efficiency. Section 4 presents budget estimates for the mass, area, and extent in terms of the net melt and advection. Section 5 presents the results of a numerical experiment that changes the wind forcing for the model, and the final section presents a short discussion of the many factors leading to the thinning of the ice and the sharp reduction in the ice extent.

\section{The coupled ice-ocean model}

\section{a. Model description}

In this study, we use the Pan-Arctic Ice-Ocean Modeling and Assimilation System (PIOMAS) based on the
Parallel Ocean and Ice Model (POIM) of Zhang and Rothrock (2003). PIOMAS consists of the Parallel Ocean Program (POP) ocean model (e.g., Smith et al. 1992; Dukowicz and Smith 1994) coupled to a multicategory thickness and enthalpy distribution (TED) sea ice model (Zhang and Rothrock 2001; Hibler 1980). The POP model is a Bryan-Cox-Semtner-type ocean model (Bryan 1969; Cox 1984; Semtner 1986) with numerous improvements, including an implicit freesurface formulation of the barotropic mode and model adaptation to parallel computing. The TED sea ice model consists of five main components: 1) a momentum equation that determines ice motion, 2) a viscousplastic ice rheology that determines the internal ice stress, 3) a heat equation that determines the ice temperature profile and ice growth or decay, 4) an ice thickness distribution equation that conserves ice mass, and 5) an enthalpy distribution equation that conserves ice thermal energy. The TED sea ice model has 12 categories each for ice thickness, ice enthalpy, and snow depth; it uses a line successive relaxation (LSR) dynamics model (Zhang and Hibler 1997) to solve the ice momentum equation with a teardrop plastic ice rheology that allows biaxial tensile stress (Zhang and Rothrock 2005).

The PIOMAS configuration is based on a generalized orthogonal curvilinear coordinate system, covering the Arctic Ocean, North Pacific, and North Atlantic. The northern grid pole is displaced into Greenland and the mean horizontal resolution is about $22 \mathrm{~km}$ for the Arctic Ocean. The ocean model's vertical dimension has 30 levels of varying thicknesses, with six 5-m-thick levels for the surface waters. The POP ocean model is modified so that open boundary conditions can be specified along the model's southern boundaries along $43^{\circ} \mathrm{N}$. The open boundary conditions of sea surface height and ocean velocity, temperature, and salinity are obtained from a run of a global version of POIM (Zhang 2005).

The model is forced with daily National Centers for Environmental Prediction-National Center for Atmospheric Research (NCEP-NCAR) reanalysis (Kalnay et al. 1996) fields of 10-m surface winds, 2-m surface air temperature (SAT), specific humidity, precipitation, evaporation, downwelling longwave radiation (DLR), sea level pressure (SLP), and cloud fraction. SAT and cloud fraction are used to calculate downwelling shortwave radiation (DSR) following Parkinson and Washington (1979). No data assimilation is used in this study.

\section{b. Validation}

Figure 1 shows a time series of modeled and satelliteobserved September sea ice extents from 1979 through 

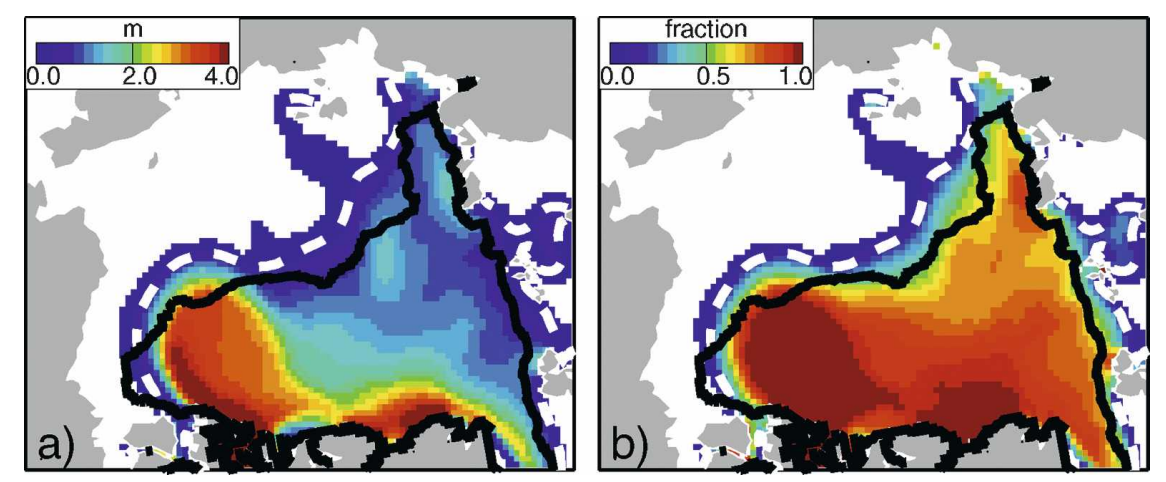

FIG. 2. Simulated (a) ice thickness and (b) ice concentration for September 2007. The observed ice extent line ( 0.15 contour $)$ is drawn in black and the simulated ice extent is in white (dashed). The observed extent is from the SSM/I NASA team ice concentration dataset (Meier et al. 2006).

2007. The modeled September ice extent is highly correlated with the observations, with a linear correlation coefficient of $R=0.92(R=0.83$ if the trends are removed). The model overestimates ice area and extent in 2007 relative to the observations. It underestimates the large drop in 2007 extent, so it also possibly underestimates ice thickness decreases as well. Figure 2 shows maps of the mean September simulated ice thickness and the simulated and satellite-observed ice extents. The modeled ice extent (the region with ice concentrations greater than 0.15 ) exceeds that of the observations but there is a good match in the overall pattern. The simulated ice motion is validated through comparison with buoy tracks from the International Arctic Buoy Program. The annual mean vector correlation for daily velocities is $R=0.88$, with simulated ice speed exceeding observations by $8 \%$ on an annual average. The bias in recent years, since 1991, is less, av- eraging 5\%, and in 2007 it was near zero. The overestimate of the ice speed in some years may mean that the advective processes in the analysis below are overestimated as well.

The model ice draft is compared to recent observations of the ice draft made with upward-looking sonar (ULS) instruments moored to the ocean floor in five locations (Fig. 3) between 2001 and 2005. The ice draft exhibits a bias between the North Pole, where the model drafts are too thin, and the Beaufort Sea, where the model drafts are too thick. This bias has been observed in a similar model before (Rothrock et al. 2003; Lindsay and Zhang 2005). Within each region the correlation of the model draft with the measured draft is high: $R=$ 0.81 at the North Pole and $R=0.86$ in the Beaufort Sea. The correlation between the model-simulated ice thickness and submarine observations available over 198797 is 0.71 , with a mean bias of $0.06 \mathrm{~m}$.
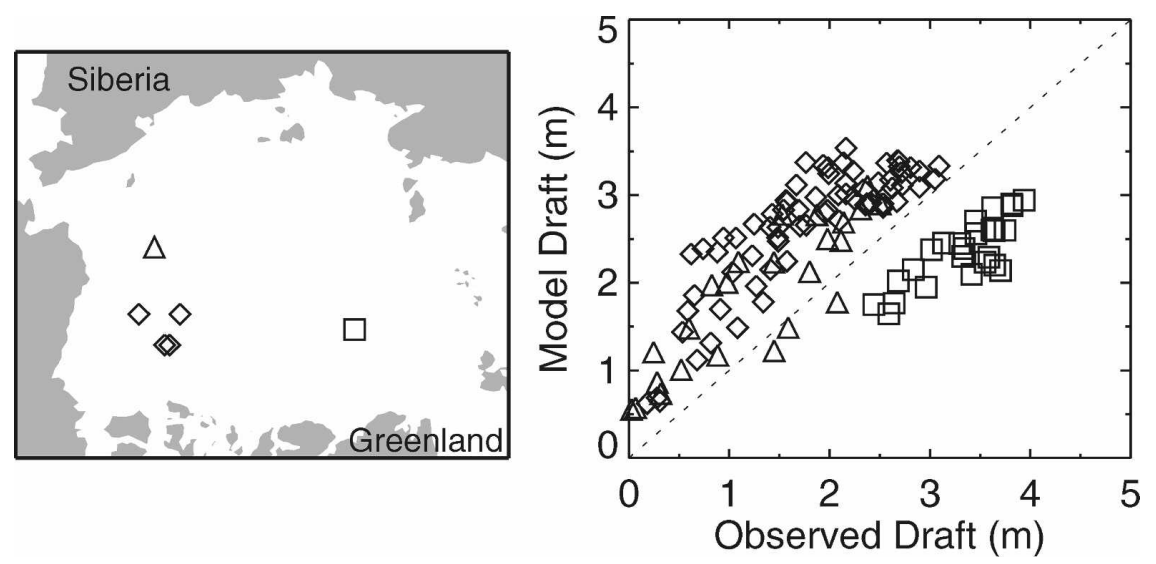

FIG. 3. Comparison of the model draft to ULS draft measurements from five mooring locations: triangle, Institute of Ocean Sciences, 2003-05; diamonds, Beaufort Gyre Exploration Project, 2003-05; and square, North Pole Environmental Observatory, 2001-03. 


\section{Basinwide properties of the ice cover}

We first consider area-averaged quantities to investigate temporal changes in the ice. Our analysis focuses on the Arctic Ocean basin defined to include the marginal seas but not including the Bering, Barents, and Greenland Seas nor the Canadian Archipelago. Clear definitions for different diagnostics of sea ice are needed. Mean ice thickness in our analysis includes the open-water category. Ice volume is the total volume of sea ice and is thus the product of the mean ice thickness and the total area of a region. Here, we report the volume in terms of the mean ice thickness over the Arctic Ocean basin. Ice area is the total area of a region covered by sea ice. Ice concentration is the fractional area of a region that is covered with sea ice. Ice extent refers to the area that is covered by ice with a concentration of greater than 0.15 . Thus, the ice area is equal to or smaller than the ice extent because little of the ice is in regions with concentrations of less than 0.15 .

\section{a. Ice thickness, area, and extent}

The simulated mean ice thicknesses in May (annual maximum) and September (annual minimum) for the Arctic Ocean are shown in Fig. 4. The thickness began its modern decline in about 1987 with a period of very strong positive Arctic Oscillation index in 1989-93 (Rigor and Wallace 2004; Lindsay and Zhang 2005). The 1987-2006 trend lines in Fig. 4 show a rate of reduction in the thickness of $-0.47 \mathrm{~m} \mathrm{decade}^{-1}$ in May and $-0.57 \mathrm{~m} \mathrm{decade}^{-1}$ in September (see Table 1). If extrapolated forward in time (always a chancy exercise and not meant as a forecast here), the September ice will have zero thickness between 2025 and 2030. Significance tests for the trend are not appropriate because the fit interval was selected based on the data.

In a changing climate, a meaningful benchmark for the magnitude of the anomalies is with respect to the anomalies about the trend. We use the quantity $\sigma$, defined as the standard deviation of the residuals of the fit for the linear trend, to measure how far from the trend line a quantity is relative to the variability about the trend, that is, how unusual it is relative to the trend. The 2007 mean thickness values are record minima, but are not far from the trend lines for May and September, $-0.19 \sigma$ and $-0.75 \sigma$, respectively. The trend line accounts for $83 \%$ of the variance $\left(R^{2}\right)$ in the September mean ice thickness.

The September ice area and extent also show consistent declines since 1987 but the interannual variability is much higher, as reflected in the percent of the variance explained by the trend lines, $39 \%$ and $17 \%$, respectively. However, the deviations of the 2007 values
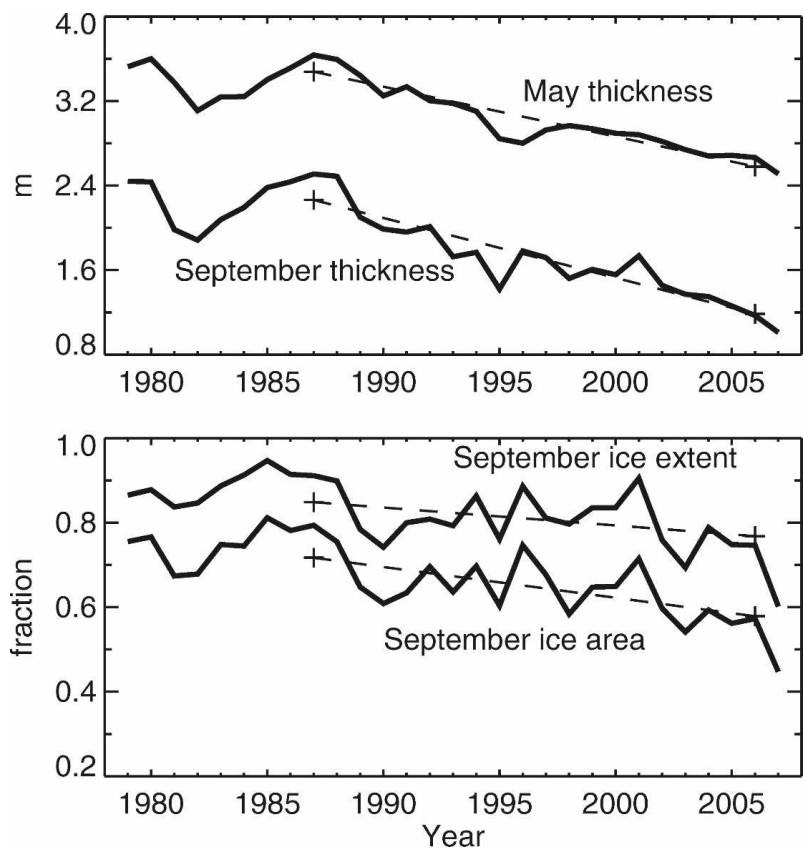

FIG. 4. (top) Annual mean ice thickness in the Arctic Ocean in May and September and (bottom) the September fractional ice area and ice extent. The trend lines for the period 1987-2006 are shown as dotted lines.

from the trend lines are much higher than for the ice thickness, $-2.24 \sigma$ and $-2.86 \sigma$ (Table 1 ).

Why is the relative variance about the trend line $(1-$ $R^{2}$ ) for ice area and extent greater than for the thickness? The relative variances for the ice area and extent are larger because a small change in ice thickness can result in a large change in the area covered by ice. For thin ice a small amount of melt can rapidly decrease the ice area or, conversely, ice growth can rapidly cover large areas of open water with ice. The ice extent is further subject to variable amounts of movement of the ice pack, which depends on wind forcing but also on ice compactness, which may limit how much the ice can move. The compactness of the ice pack (the ratio of ice area to ice extent) in August, the month of minimum compactness, has been decreasing in the last $20 \mathrm{yr}$ because the area is declining faster than the extent. A less compact ice pack is more easily moved to one side of the basin and thus allows for greater variability in the ice extent.

\section{b. Thickness distribution}

The relationship between changes in ice thickness and area is represented in Fig. 5, which shows the cumulative distribution of the ice thickness averaged over the Arctic Ocean for the months of May and September, $G_{\text {May }}(h)$ and $G_{\text {Sept }}(h)$. For both months, more area is covered with thin ice in recent years. In May 1987, 
TABLE 1. Ice thickness, area, and extent for the Arctic Ocean, May-September.*

\begin{tabular}{|c|c|c|c|c|c|c|}
\hline & May mean & September mean & Total melt & Total export & Total change & Fram Strait export \\
\hline \multicolumn{7}{|l|}{ Ice thickness } \\
\hline 1987-2006 mean (m) & 3.03 & 1.73 & -1.15 & -0.10 & -1.25 & -0.11 \\
\hline Trend $\left(\mathrm{m} \mathrm{decade}{ }^{-1}\right)$ & -0.47 & -0.57 & -0.12 & 0.04 & -0.11 & 0.05 \\
\hline$R^{2}$ of trend & 0.87 & 0.83 & 0.31 & 0.04 & 0.19 & 0.05 \\
\hline $2007(\mathrm{~m})$ & 2.51 & 1.01 & -1.35 & -0.13 & -1.48 & -0.10 \\
\hline 2007 trend anomaly $(\mathrm{m})$ & -0.02 & -0.12 & -0.07 & -0.05 & -0.11 & -0.04 \\
\hline$\sigma$ & -0.19 & -0.75 & -0.62 & -0.97 & -0.84 & -1.11 \\
\hline \multicolumn{7}{|l|}{ Ice area } \\
\hline 1987-2006 mean (fraction) & 0.97 & 0.65 & -0.21 & -0.03 & -0.22 & -0.03 \\
\hline Trend (fraction decade ${ }^{-1}$ ) & 0.00 & -0.07 & -0.05 & 0.09 & -0.06 & 0.05 \\
\hline$R^{2}$ of trend & 0.02 & 0.39 & 0.31 & 0.09 & 0.32 & 0.05 \\
\hline 2007 & 0.97 & 0.45 & -0.38 & -0.10 & -0.45 & -0.04 \\
\hline 2007 trend anomaly (fraction) & 0.01 & -0.12 & -0.11 & -0.05 & -0.16 & -0.01 \\
\hline$\sigma$ & 0.49 & -2.24 & -2.31 & -1.75 & -2.74 & -1.38 \\
\hline \multicolumn{7}{|l|}{ Ice extent } \\
\hline 1987-2006 mean (fraction) & 1.00 & 0.81 & & & -0.19 & -0.04 \\
\hline Trend (fraction decade ${ }^{-1}$ ) & 0.00 & -0.07 & & & -0.06 & 0.11 \\
\hline $\mathrm{R}^{2}$ of trend & 0.07 & 0.17 & & & 0.18 & 0.11 \\
\hline 2007 & 1.00 & 0.60 & & & -0.40 & -0.05 \\
\hline 2007 trend anomaly (fraction) & 0.00 & -0.16 & & & -0.16 & -0.02 \\
\hline$\sigma$ & 0.22 & -2.86 & & & $-\mathbf{2 . 8 9}$ & -1.48 \\
\hline
\end{tabular}

* The May and September columns are the mean for the month. The melt and export columns are the total contribution of each process for 1 May-30 Sept averaged over the basin. The Fram Strait export is the total for May-September; the volume export is expressed as meters of ice over the entire basin and the area and extent export as a fraction of the basin area. Here, $\sigma$ is the trend anomaly divided by the std dev of the residuals of the linear trend line. Values with magnitude greater than 2 are set in boldface.

about $50 \%$ of the area (the 0.5 line) is covered by ice thinner than $2.0 \mathrm{~m}$ and in May 2007 about $70 \%$ of the area (the 0.7 line) has ice less than $2 \mathrm{~m}$ thick. The area covered by ice less than $1 \mathrm{~m}$ thick in September increases from $50 \%$ in 1987 to $70 \%$ in 2007 . The most notable aspect of the changes in the simulated ice thickness distribution is that 2007 is not unusual when considered as part of a $20-\mathrm{yr}$ trend that started in about 1987. In September 2007 about $60 \%$ of the area of the basin was ice free. The 0.6 line has been dropping toward the zero thickness level since 1987, albeit with some considerable interannual variability.

The reduction in the September ice area arises from both a decline in the area covered by thick ice and a steady increase in the amount of summer ice melt and export. The dashed line in the May distribution plot shows the mean loss of ice over the Arctic basin from May to September (the difference in the two ice thickness lines in Fig. 4 and also the "change" column in Table 1). A rough approximation of the amount of open water in September may be found in the May thickness distribution as the amount of area in May with ice thickness less than the amount lost through melt and export from May through September, $\Delta h$ : $G_{\text {Sept }}(0)=G_{\text {May }}(\Delta h)$. In 1987 the equivalent of slightly more than $1.0 \mathrm{~m}$ of ice was either melted or exported, enough to produce $20 \%-30 \%$ open water as seen in the
September distribution at zero thickness. In 2007 the summer loss of ice is near $1.5 \mathrm{~m}$. This amount of ice loss would have produced $30 \%-40 \%$ open water in 1987 , but with the changes in the thickness distribution, it produces $50 \%-60 \%$ open water in 2007 . This relationship between the ice thickness distribution and the summer melt is summarized as the open-water formation efficiency.

This concept was introduced by Holland et al. (2006) to analyze the nature of abrupt ice declines seen in general circulation model simulations. The open-water formation efficiency (OWFE) is the open-water fraction formed between May and September for each meter of ice melt. We expect that the OWFE would increase if more of the spring ice area is thin. As with the thickness distribution, the year 2007 can also be viewed as being consistent with recent trends in terms of the OWFE. Figure 6 shows the OWFE over the Arctic Ocean and the OWFE plotted against the mean ice thickness in March. The years are color coded to make it apparent that the most recent year has the greatest OWFE. In 2007 more open water was formed per meter of melt than in any other year. This rate, however, is not unexpected given the gradual increase in OWFE seen over the past decades. The OWFE is expected to increase sharply as the ice thickness in March decreases even more (Holland et al. 2006). 

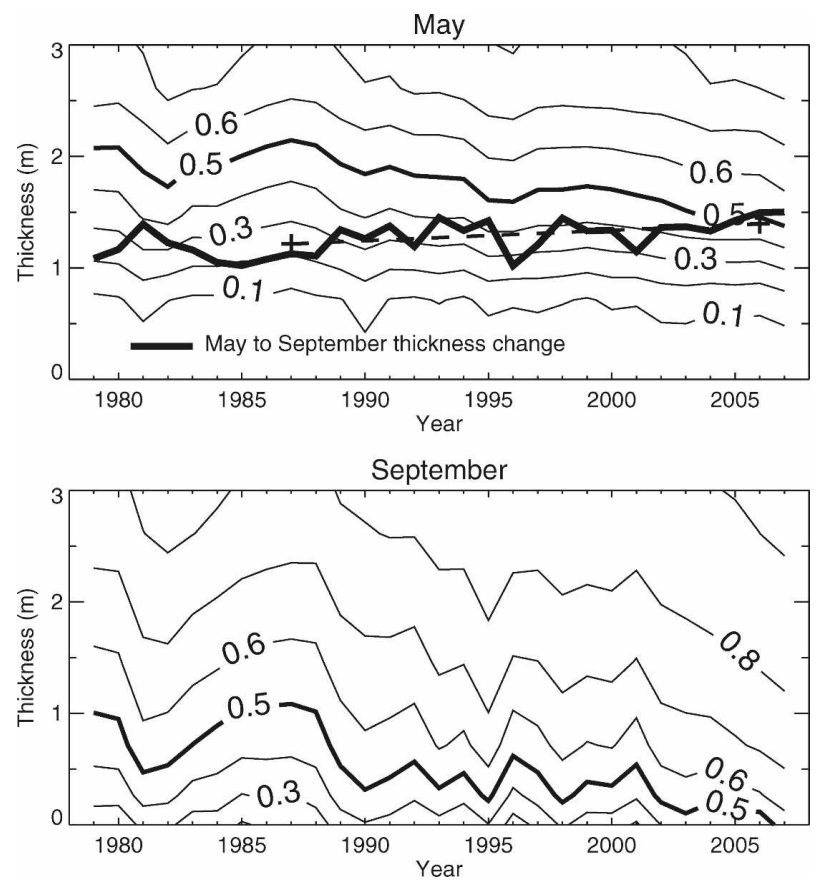

FIG. 5. May and September cumulative ice thickness distributions for the Arctic Ocean. The contours show the fraction of the total area with ice less than the indicated thickness. The median ice thickness line, marked as 0.5 , is set in boldface. The MaySeptember mean ice thickness loss, a thick line, and the linear trend line are also shown in the May plot.

\section{Budgets for the ice mass, area, and extent}

\section{a. Ice mass budget}

To gain a better understanding of the physical processes that link changes in ice properties over the past
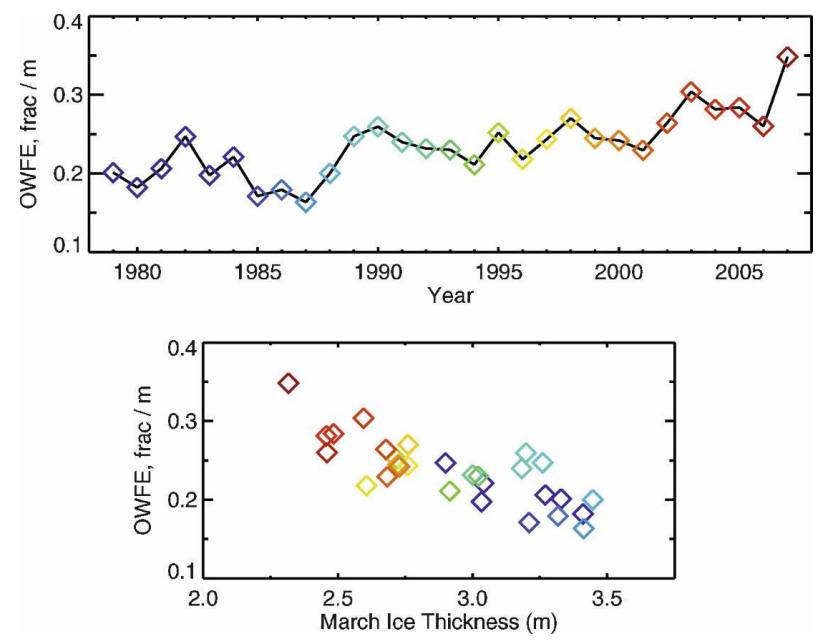

FIG. 6. The open water formation efficiency versus the year and versus the mean March ice thicknesses. The colors in the bottom panel correspond to the year.
$29 \mathrm{yr}$ with the sea ice anomaly of 2007 , we compute budgets that allow the separation of advective and thermodynamic processes. To understand how ice area and mass are affected by these processes during summer, separate mass and area budgets are computed for the melt season. Changes in the ice mass within the Arctic Ocean are due to ice export or ice production (either melt or freezing). The local change in ice thickness $\Delta h$ over a time interval $\Delta t$ can be described by a simple imbalance between the local net thermodynamic ice production $\Delta h_{\mathrm{p}}$ and the local net ice advection (mass flux convergence), $\Delta h_{\text {adv }}=-\nabla(\mathbf{u} h) \Delta t$, due to ice motion $\mathbf{u}$, such that $\Delta h=\Delta h_{\mathrm{p}}+\Delta h_{\mathrm{adv}}$. Integrating the imbalance between local ice advection and ice production over the whole Arctic Ocean yields $\Delta H=P_{h}+E_{h}$, where the change in the basin-wide mean ice thickness $(\Delta H)$ in a given time is due to an imbalance between the total ice production $P$ inside the ocean domain and ice export $E$ at its open boundaries, mainly at Fram Strait.

Figure 7 shows the May-September total ice export and production for the Arctic Ocean. Ice production is substantially negative, reflecting the strong summer melt. [Note that the total annual production is in fact positive, reflecting net growth, which is approximately balanced by the net export; e.g., Steele and Flato (2000)]. May-September ice production is more variable than the ice export and shows a general downward trend since 1987. The total melt in 2007, a near-record maximum, is not far below the 1987-2006 trend line $(-0.62 \sigma$; Table 1$)$. The net summer ice export in 2007 is farther below the trend line relative to the variability $(-0.97 \sigma)$. The trend slopes slightly upward, indicating decreasing ice export due to thinner ice transiting Fram Strait (Lindsay and Zhang 2005).

The annual cycle of the mean ice thickness for the

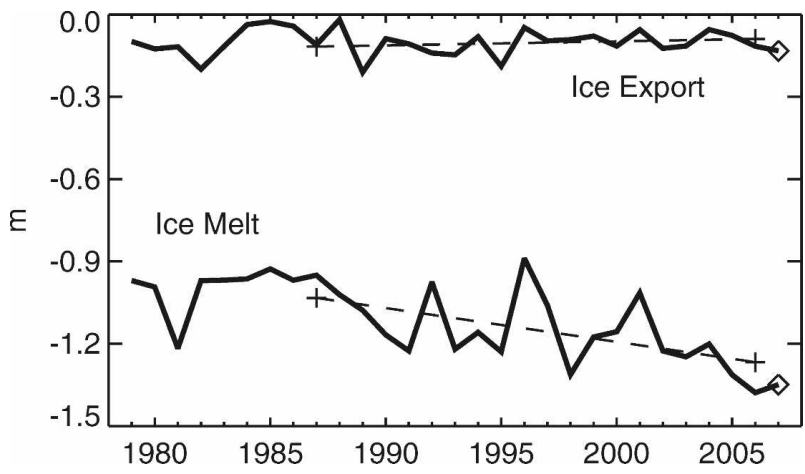

FIG. 7. May-September net ice mass export and ice production for the Arctic Ocean. The values for 2007 are marked with diamonds and the trend lines for the period 1987-2006 are shown as dashed lines. 

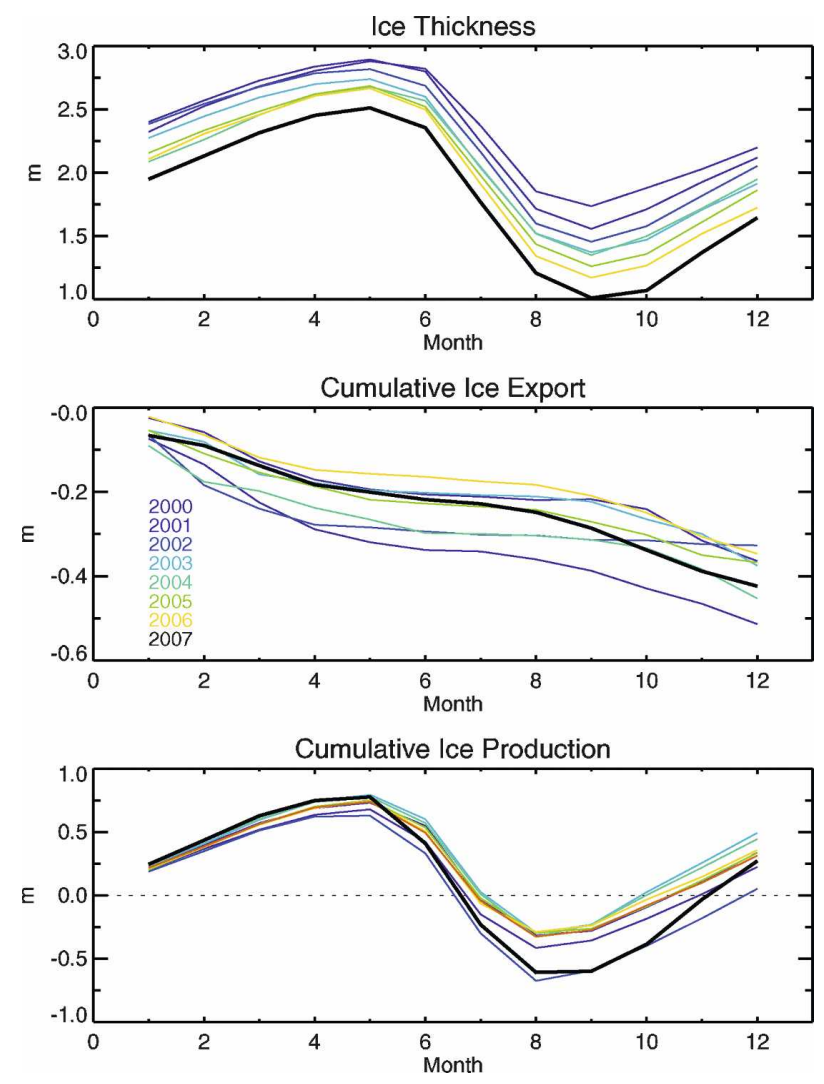

FIG. 8. Mean ice thickness, cumulative net ice export, and cumulative ice production, starting in January, for the most recent $8 \mathrm{yr}$.

most recent 8 yr is shown in Fig. 8. The mean thickness for 2007 is below that of all the recent years and is particularly low in the early fall. The cumulative ice export since the first of the year is not anomalous in 2007 compared to recent years, although there is greatly accelerated export in the late summer (as in Zhang et al. 2008). However, the cumulative ice production, while it began the year at a greater than normal rate, was below normal by the end of the summer. July shows a steep drop in production (increased melting) compared to recent years, while the late fall shows a rapid increase in ice production as would be expected for the large areas of thin ice and open water when the sun sets.

The anomalous ice production and advection terms for 2007, integrated from May through September, are shown in the maps in Fig. 9. A large area of anomalous advective ice mass loss in the Pacific sector extends toward the North Pole. This strong transpolar drift is also observed by the drift of buoys and in the Advanced Microwave Sounding Radiometer for the Earth Observing System (AMSR-E) passive microwave measurements (Kwok 2008). The anomalous drift is on the
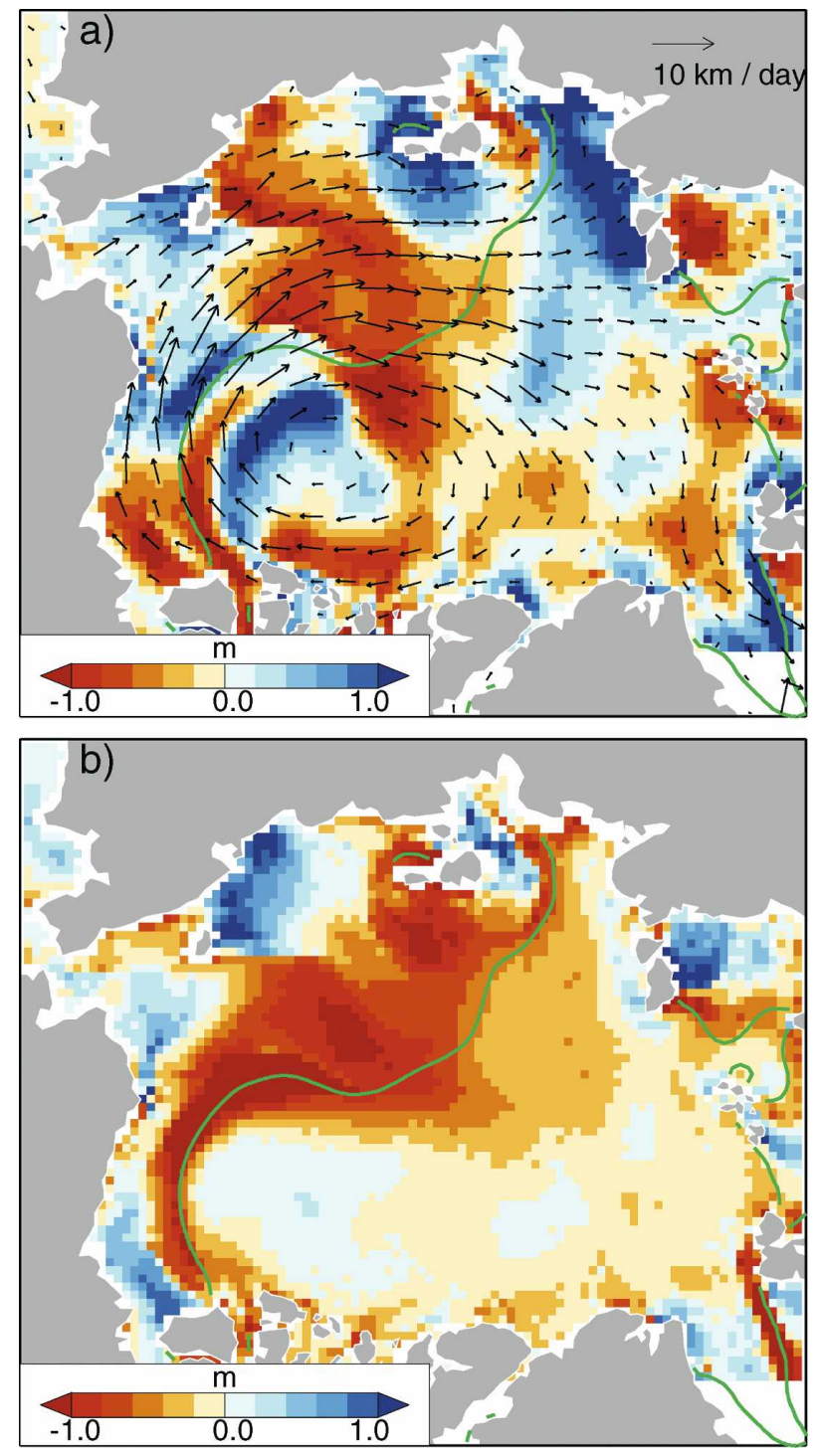

FIG. 9. (a) May-September anomalous net ice mass advection and (b) ice production for 2007 . The anomalous mean ice velocity over the 5-month period is shown as vectors and a green line shows the simulated ice extent in September. The anomalies are relative to the 1979-2006 period.

order of $1000 \mathrm{~km}$ over the summer (half the length of the box containing the color bar). An area of anomalous ice mass convergence is seen near the Laptev Sea and northwest near Severnaya Zemlya. A broad band of anomalous melt, over $1 \mathrm{~m}$ in some locations, extends from the Beaufort Sea to the Laptev Sea, mostly south of the final ice edge. In most of the Eurasian sector, the melt rate was near normal. Small areas of positive anomaly in the East Siberian Sea and southern Beaufort Sea are caused by a lack of ice, so the ice loss there is less than normal. Averaged over the basin, there was $1.48 \mathrm{~m}$ of ice loss from the first of May to the end of 
September in 2007 , of which $91 \%$ was from melt and $9 \%$ from export. This loss was $-0.11 \mathrm{~m}$ less than the 1987-2006 trend line $(-0.84 \sigma)$.

\section{b. Ice area budget}

As with the ice thickness, a budget may be formulated for the area covered by ice. The changes in the ice area during the summer melt can be quite different from changes in the ice thickness. If the ice is thick, melt may not significantly change the ice-covered area, while if it is thin, it will. The ice area budget shows where and when changes in the ice area, as opposed to changes in the ice thickness, are caused by melt or ice area convergence. The change in the fractional area covered by ice (the ice concentration) can be computed in terms of the production of the area due to melt or freezing and the change due to advection. Let the fraction of the area covered by sea ice be $a$, the area production due to net ice area advection (net area convergence) be $\Delta a_{\mathrm{adv}}=-\boldsymbol{\nabla}(\mathbf{u} a) \Delta t$, and that due to production (thermodynamic melt or freezing) be $\Delta a_{p}$ (some ice area can be lost to local ridging of ice and it is also included in this term). The change in the ice area over a time period is then $\Delta a=\Delta a_{\mathrm{p}}+\Delta a_{\text {adv }}$.

The monthly change in the ice-covered area and the monthly advection of ice area are computed from the monthly model output (mean ice velocity and ice area) for each month and each location, and the thermodynamic production is determined as a residual. Integrating the imbalance between local ice advection and ice production over the whole Arctic Ocean yields $\Delta A=$ $P_{a}+E_{a}$, where the change in the basin-wide mean ice area $\Delta A$ in a given time is due to an imbalance between the total ice area production $P_{a}$ inside the ocean domain and the ice area export $E_{a}$ at its open boundaries, mainly at Fram Strait.

The spatial patterns of melt and advection are similar to those for the ice thickness, but the budget is able to quantify just what the proportion of the ice area loss is from each of these two processes (see Table 1). The annual May-September ice area losses from advection and melt are represented in Fig. 10. Both the melt and export terms for 2007 are below their trend lines $(-2.31$ $\sigma$ and $-1.75 \sigma$, respectively; Table 1 ). The spatial patterns of the net area advection anomalies and area production anomalies are shown in Fig. 11. These maps clearly show that the melt in 2007 created most of the open water in the Pacific sector, similar to the mass melt pattern, but more widespread. Advection is also important in some locations and a broad region of net advective loss is formed in the Transpolar Drift Stream as low ice concentrations are advected farther north. Ice area divergence is important primarily in the Beau-

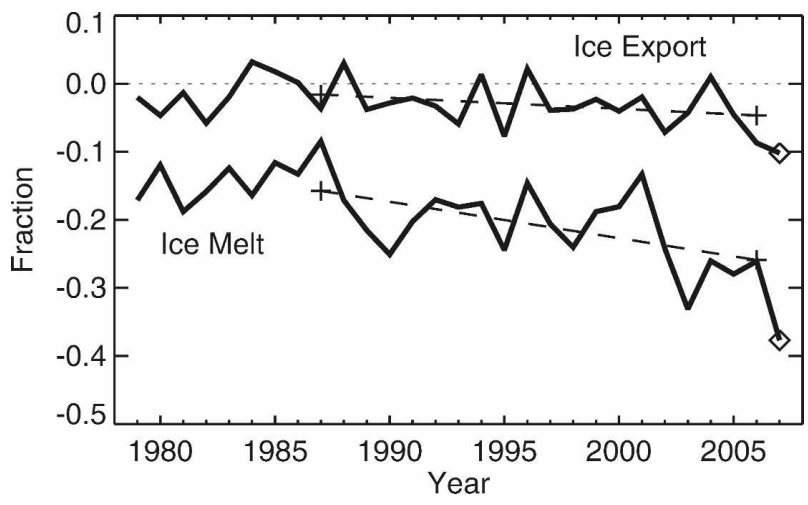

FIG. 10. May-September changes in the fractional ice area within the Arctic Ocean due to the area export and due to melt.

fort Sea. Some area convergence is seen in the region north of Canada and northwest of the Laptev Sea. The area budget shows that, in $2007,38 \%$ of the basin was cleared of ice by melt and $10 \%$ by export (Table 1 ).

\section{c. Ice extent}

The persistent southerly winds in some parts of the Pacific sector had an important influence on the ice extent in that the edge was moved $1000 \mathrm{~km}$ north. Figure 12 shows the end-of-August ice edge if it were advected backward 4 months to the likely end-of-April position using the monthly mean ice velocities. A large region of the Pacific sector was cleared of ice by the persistent southerly winds. The area between the endof-May and end-of-August positions (the shaded area in Fig. 12) amounts to $0.85 \times 10^{6} \mathrm{~km}^{2}$, or $13 \%$ of the basin. According to these simulations, of the $40 \%$ of the basin that was ice free in September, about one-third ( $13 \% / 40 \%)$ was created by ice moving out of the Pacific sector.

The area cleared of ice by the persistent southerly winds in the simulations is about $75 \%$ more than that obtained in the observational study by Kwok (2008). He used AMSR-E 18-GHz brightness temperature images to track the summer ice (June-September) for the years 2003-07 and determined that in 2007 the net ice area exported from the Pacific sector to the Atlantic sector over a straight line across the basin amounted to $0.48 \times 10^{6} \mathrm{~km}^{2}, 15 \%$ of the summer ice retreat. Much of the discrepancy between our estimate and Kwok's may be due to the different methods used to determine the ice transport, but the difference is also due to errors in the model's representation of ice velocity.

If we divide the basin into an Atlantic sector and a Pacific sector based on the ice edge in September, the Pacific sector occupies $38 \%$ of the basin. From May through September, ice representing $13 \%$ of the basin 

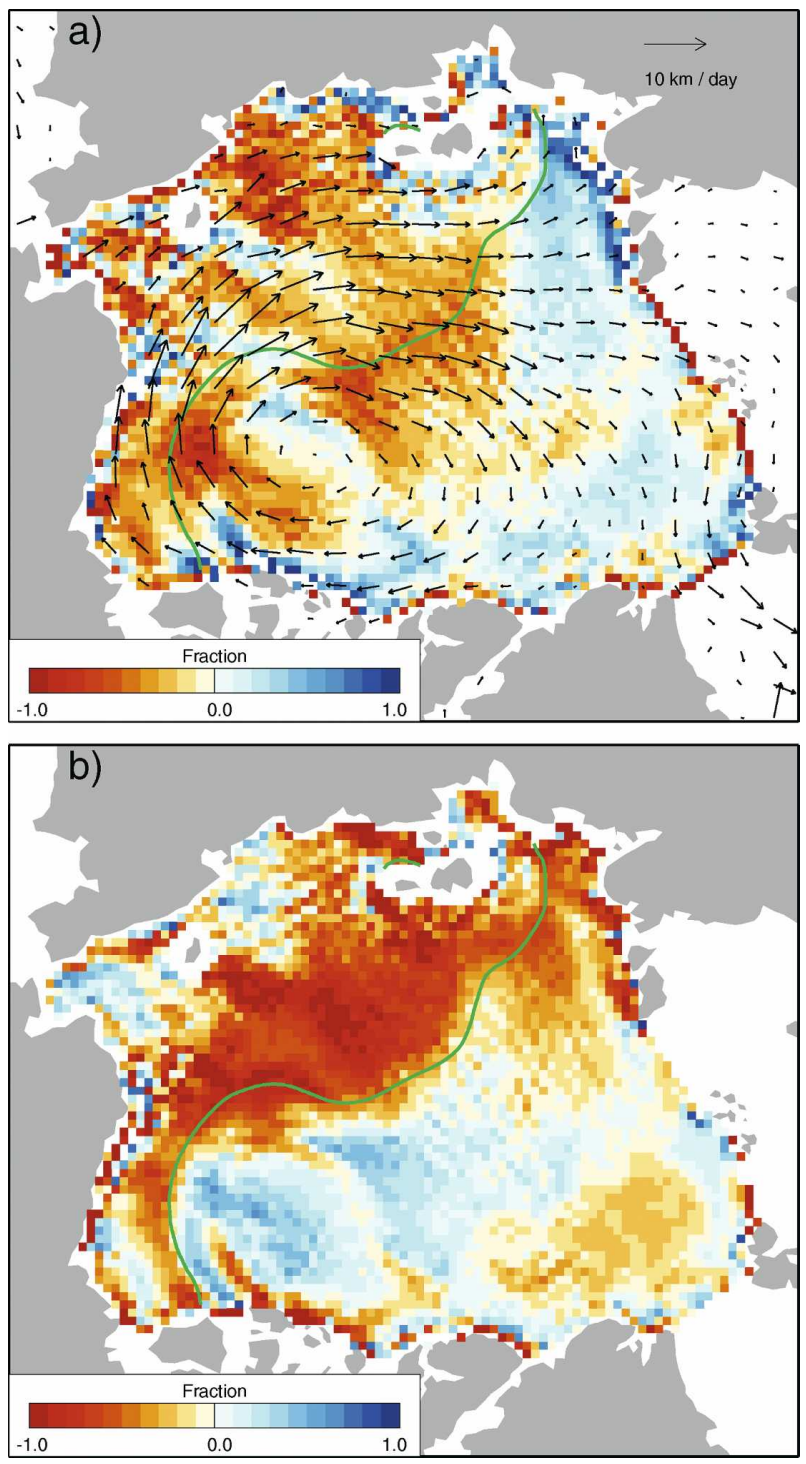

FIG. 11. (a) May-September anomalous net ice area advection and (b) ice area melt for 2007. The anomalous ice velocity over the 5-month period is shown as vectors and a green line shows the simulated ice extent in September.

was advected out of the Pacific sector and $25 \%$ was removed by melt. In the Atlantic sector, ice representing $13 \%$ of the basin area was advected in from the Pacific side, 4\% was exported through Fram Strait (Table 1), 2\% through other passages, and $7 \%$ was lost by melt. The total net convergence of the ice pack in the Atlantic sector amounted to only $1 \%$ of the basin area.

\section{Sensitivity experiment with alternate winds}

Was the atmospheric forcing of 2007 particularly unusual or would winds or air temperatures from other

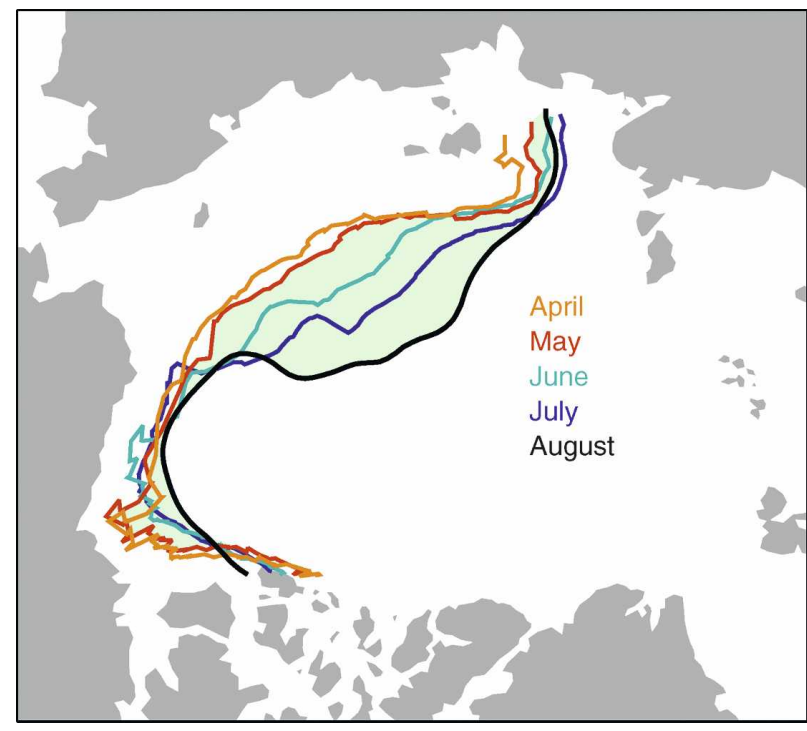

FIG. 12. The end-of-August 2007 ice edge is traced back 4 months using the monthly mean ice velocity fields.

years have produced ice extents just as low? This question is addressed with model simulations in which the wind forcing is taken from each of the last $28 \mathrm{yr}$ but the daily thermal forcings (SAT, DLW, and DSW) are taken to be always the same, the 28-yr mean from 1979 to 2006. The initial ice and ocean conditions each year are always from the recent thin-ice conditions of 1 January 2007. This experiment is designed to test the importance of the 2007 winds in establishing the large ice retreat and to determine if the 2007 winds were highly unusual in this regard. The results are compared to a control run (Fig. 13, dashed line), which is a retrospective analysis in which all forcings change normally and January conditions evolve normally.

The 2007 result for the experiment shows that the ice is both thicker and more extensive than in the control run because of the much cooler thermal forcing derived from the mean of the previous years. However, the winds from 2007 did not produce an ice thickness or extent that was particularly unusual compared to the other years in the experiment. Winds from 10 of the years produced ice thinner than that from 2007 and winds from five years produced ice extents lower than those from 2007, all given the same thermal forcing. Even though constant thermal forcings dampen the response of the system to the different wind forcings because the air temperature cannot respond to the changing surface conditions, we note that winds alone can produce significant variability in the ice extent from year to year. We therefore conclude that 2007 was not an unusual year in this respect. Winds that pushed the ice from the Pacific side of the basin to the Atlantic side 

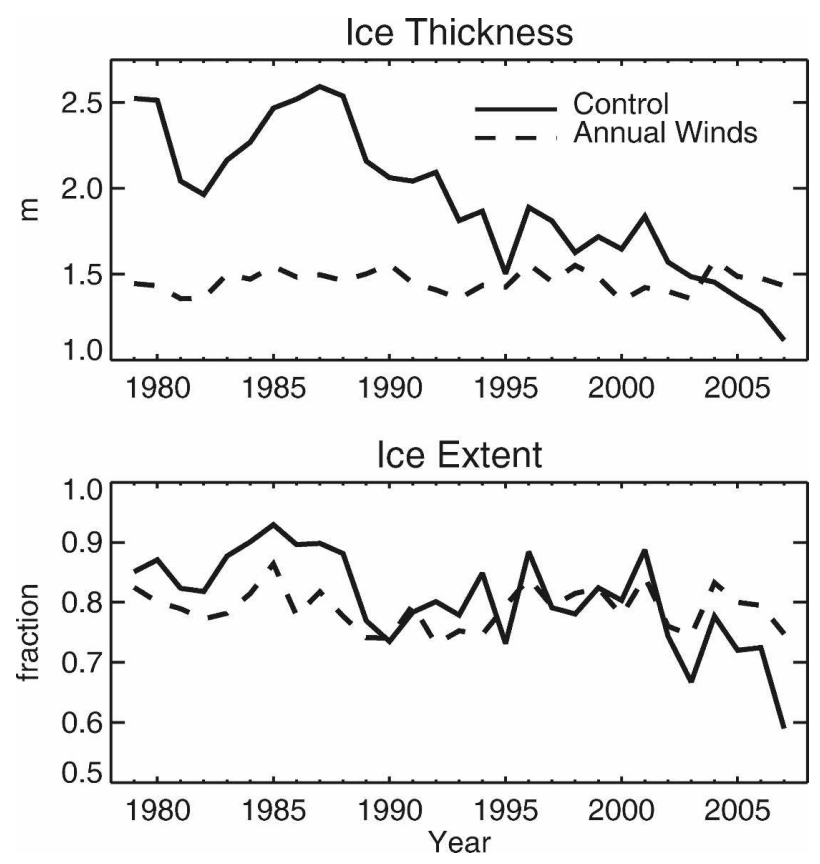

FIG. 13. September ice thickness and extent over the Arctic Ocean for the control run and the annual winds experiment.

were not highly unusual in their impact on the ice extent and would not have produced the ice extent anomaly without prior thinning or anomalous melt.

Analogous experiments (not shown) were also performed with January initial conditions taken from 2007 and both the winds and the thermal forcings taken from each of the past years. The ice thickness is thinner than the control, but consistently thicker than in 2007. However, the ice extent is very strongly forced by the thermal fluxes, so the ice extent more closely follows the control run. These experiments demonstrate the importance of ice-ocean-atmosphere interactions and illustrate that only limited conclusions can be drawn from uncoupled models about the relative importance of thermal forcings.

\section{Discussion and conclusions}

The total volume of summer sea ice has been on a downward trend since 1987, and the volume in the summer of 2007 was not far below the trend line. While the amount of ice volume melt and ice export in summer 2007 were higher than normal, they were not greatly different from what might be expected based on the trends over the last $20 \mathrm{yr}$. Thus, the unusual retreat of the sea ice was preconditioned by decades of gradually warming temperatures and the replacement of older ice by younger ice, resulting in a thinner ice pack. Though winds were anomalous during 2007, it appears that they would have had little impact on the sea ice extent without this preconditioning.

The ice has now reached a stage in the thinning process where large reductions in ice extent can be expected for modest increases in the amount of melt (Maslanik et al. 2007). The thinner ice is more susceptible to large reductions in ice extent because (a) more open water is created per meter of vertical melt (the open-water formation efficiency) and (b) thinner ice is weaker and hence responds more readily to wind forcing, allowing the ice to be more easily driven away from the coast or out of the basin.

What we do not directly address in this study are the basic causes of the thinning ice pack. The fundamental cause is likely the warming of the global atmosphere and ocean due to increasing greenhouse gases, though the physical processes linking this warming to the decline in sea ice are not clear at this point. The Arctic atmosphere appears to have warmed not only at the surface, which could be a response to the thinning ice as much as a cause, but at all levels up to at least $300 \mathrm{mb}$. The Arctic warming to this level is linked to global warming in a study by Graversen et al. (2007), who conclude that much of the present warming above the surface is not due to surface changes but to atmospheric energy transport from southern latitudes.

A number of feedbacks exaggerate the warming trends. The warming of the atmosphere, particularly in the spring, has led to earlier onset of melt (Belchansky et al. 2004). This earlier melt onset changes the albedo of the snow surface in a way that has repercussions throughout the melt season. Perovich et al. (2007) conclude that the total amount of solar energy absorbed by the ice and ocean is strongly related to the date of melt onset, but only weakly related to the total duration of the melt season or the onset of freeze-up. The timing of melt onset is significant because the solar elevation is high in the late spring and a change in the surface albedo and the surface energy balance at this time propagates through the entire melt season, affecting the absorbed solar flux until the sun is again low. The increasing amounts of ice loss during the summer are largely a result of the changing albedo of the surface caused by earlier onset of melt, more thin ice, and more open water (Lindsay and Zhang 2005).

The ice-albedo feedback was particularly strong in 2007. Perovich et al. (2008) found a sixfold increase (relative to the 1990s) in bottom melt at the location of a mass balance buoy in the Beaufort Sea but only normal amounts of surface melt. This was caused by a $500 \%$ increase (relative to 1979-2005 average) in the absorbed solar flux due chiefly to more open water and a small anomaly $(6 \%)$ in downwelling solar radiation. 
The anomaly in downwelling solar radiation and potentially increased melt rates were due to persistent high pressure in the Beaufort Sea region that brought unusually clear skies (Kay et al. 2008). However, the anomalous downwelling solar flux was not a key component of the large retreat of ice in 2007 according to a modeling study by Schweiger et al. (2008). They conclude that the anomalous radiative flux was not in the region where the ice retreated most dramatically and numerical experiments without the anomaly produced ice extents similar to those with the anomaly.

The anomalous winds of 2007 contributed to the reduction in ice extent by pushing the ice to one side of the basin, but if the sea ice had been of near-normal thickness at the start of the year, the unprecedented reduction in extent would likely not have occurred. This increase in the advection of ice from the Pacific sector to the Atlantic sector may be amplified by two dynamic feedbacks, one in which thinner (and hence weaker) ice is more easily compacted (Maslanik et al. 2007) and one in which thinner ice responds more readily to wind forcing, which is manifested in higher ice drift speeds (Rampal et al. 2007). The thinner ice is more easily compacted and is flushed out of the basin more quickly. In addition, winds favorable for sequestering multiyear ice within the basin have been rare since the 1980s.

The most notable aspect of the changes in the simulated mean ice thickness and the basin-wide ice thickness distribution is that 2007 is not unusual when seen as part of a 20-yr trend that started in about 1987. Both the area coverage of thin ice at the beginning of the melt season and the total volume of ice lost during the summer have steadily increased. The combined impact of these two trends and the persistent southerly summer winds caused the 2007 ice extent reduction. The simulated ice thickness for December 2007 is at yet another minimum, so we expect the high variability and gradual mean decline in the September ice extent to continue.

Acknowledgments. This study was supported by the National Aeronautics and Space Administration (Grants NNG06GA84G, NNG04GH52G, and NNG06GA76G) and the National Science Foundation (Grants ARC0629312 and ARC-0629326). We thank Humfrey Melling, Institute of Ocean Sciences; Andrey Proshutinsky, Woods Whole Oceanographic Institute; and Dick Moritz, Polar Science Center, for ice draft data; the NOAA/Earth System Research Laboratory for the NCEP-NCAR Reanalysis data; the International Arctic Buoy Program for buoy drift track data; and the National Snow and Ice Data Center for passive microwave ice concentration data.

\section{REFERENCES}

Belchansky, G. I., D. C. Douglas, and N. G. Platonov, 2004: Duration of the Arctic sea ice melt season: Regional and interannual variability, 1979-2001. J. Climate, 17, 67-80.

Bryan, K., 1969: A numerical method for the study of the circulation of the world oceans. J. Comput. Phys., 4, 347-376.

Comiso, J., 2002: A rapidly declining perennial sea ice cover in the Arctic. Geophys. Res. Lett., 29, 1956, doi:10.1029/ 2002GL015650.

_ C. Carkinson, R. Gersten, and L. Stock, 2008: Accelerated decline in the Arctic sea ice cover. Geophys. Res. Lett., 35, L01703, doi:10.1029/2007GL031972.

Cox, M. D., 1984: A primitive equation, three-dimensional model of the oceans. GFDL Ocean Group Tech. Rep. 1, NOAA/ GFDL, 250 pp.

Dukowicz, J. K., and R. D. Smith, 1994: Implicit free-surface method for the Bryan-Cox-Semtner ocean model. J. Geophys. Res., 99, 7991-8014.

Graversen, R. G., T. Mauritsen, M. Tjernström, E. Källén, and G. Svensson, 2007: Vertical structure of recent Arctic warming. Nature, 451, 53-56.

Hibler, W. D., 1980: Modeling a variable thickness sea ice cover. Mon. Wea. Rev., 108, 1943-1973.

Holland, M., C. Bitz, and B. Tremblay, 2006: Future abrupt reductions in the summer Arctic sea ice. Geophys. Res. Lett., 33, L23503, doi:10.1029/2006GL028024.

Kalnay, E., and Coauthors, 1996: The NCEP/NCAR 40-Year Reanalysis Project. Bull. Amer. Meteor. Soc., 77, 437-471.

Kay, J. E., T. L'Ecuyer, A. Gettelman, G. Stephens, and C. O'Dell, 2008: The contribution of cloud and radiation anomalies to the 2007 Arctic sea ice extent minimum. Geophys. Res. Lett., 35, L08503, doi:10.1029/2008GL033451.

Kwok, R., 2008: Summer sea ice motion from the $18 \mathrm{GHz}$ channel of AMSR-E and the exchange of sea ice between the Pacific and Atlantic sectors. Geophys. Res. Lett., 35, L03504, doi:10.1029/2007GL032692.

Lindsay, R., and J. Zhang, 2005: The thinning of Arctic sea ice, 1988-2003: Have we passed a tipping point? J. Climate, 18, 4879-4894.

Maslanik, J., C. Fowler, J. Stroeve, S. Drobot, J. Zwally, D. Yi, and W. Emery, 2007: A younger, thinner Arctic ice cover: Increased potential for rapid, extensive sea-ice loss. Geophys. Res. Lett., 34, L24501, doi:10.1029/2007GL032043.

Meier, W., F. Fetterer, K. Knowles, M. Savoie, and M. J. Brodzik, cited 2006: Sea ice concentrations from Nimbus-7 SMMR and DMSP SSM/I passive microwave data. National Snow and Ice Data Center, Boulder, Colorado, digital media. [Available online at http://nsidc.org/data/nsidc-0051.html.]

_ J. Stroeve, and F. Fetterer, 2007: Whither Arctic sea ice? A clear signal of decline regionally, seasonally and extending beyond the satellite record. Ann. Glaciol., 46, 428-434.

Parkinson, C. L., and W. M. Washington, 1979: Large-scale numerical-model of sea ice. J. Geophys. Res., 84, 311-337.

_- and D. Cavalieri, 2008: Arctic sea ice variability and trends, 1979-2006. J. Geophys. Res., 113, C07003, doi:10.1029/ 2007JC004558.

Perovich, D. K., S. V. Nghiem, T. Markus, and A. Schweiger, 2007: Seasonal evolution and interannual variability of the local solar energy absorbed by the Arctic sea ice-ocean system. J. Geophys. Res., 112, C03005, doi:10.1029/ 2006JC003558. 
- J. A. Richter-Menge, K. F. Jones, and B. Light, 2008: Sunlight, water, and ice: Extreme Arctic sea ice melt during the summer of 2007. Geophys. Res. Lett., 35, L11501, doi:10.1029/ 2008 GL034007.

Rampal, P., J. Weiss, and D. Marsan, 2007: Evidence for significant acceleration of arctic sea ice drift over the last 25 years. Eos, Trans. Amer. Geophys. Union, 88 (Fall Meeting Suppl.), Abstract C11B-0438.

Rigor, I. G., and J. M. Wallace, 2004: Variations in age of Arctic sea ice and summer sea-ice extent. Geophys. Res. Lett., 31, L09401, doi:10.1029/2004GL019492.

— _ _ , and R. Colony, 2002: Response of sea ice to the Arctic Oscillation. J. Climate, 15, 2648-2663.

Rothrock, D. A., J. Zhang, and Y. Yu, 2003: The Arctic ice thickness anomaly of the 1990s: A consistent view from observations and models. J. Geophys. Res., 108, 3083, doi:10.1029/ 2001JC001208.

Schweiger, A. J., J. Zhang, R. W. Lindsay, and M. Steele, 2008: Did unusually sunny skies help drive the record sea ice minimum of 2007? Geophys. Res. Lett., 35, L10503, doi:10.1029/ 2008 GL033463.

Semtner, A. J., Jr., 1986: Finite-difference formulation of a World Ocean model. Advanced Physical Oceanographic Numerical Modeling, J. O'Brien, Ed., NATO ASI Series C, Vol. 186, D. Reidel, 187-202.

Smith, R. D., J. K. Dukowicz, and R. C. Malone, 1992: Parallel ocean general circulation modeling. Physica D, 60, 38-61.
Steele, M., and G. Flato, 2000: Sea ice growth, melt, and modeling: A survey. The Freshwater Budget of the Arctic Ocean, E. L. Lewis, Ed., NATO Advanced Research Workshop Series, Kluwer, 549-587.

Stroeve, J., M. Serreze, S. Drobot, S. Gearhead, M. Holland, J. Maslanik, W. Meier, and T. Scambos, 2008: Arctic sea ice extent plummets in 2007. Eos, Trans. Amer. Geophys. Union, 89 (2), 13-14.

Zhang, J., 2005: Warming of the arctic ice-ocean system is faster than the global average since the 1960s. Geophys. Res. Lett., 32, L19602, doi:10.1029/2005GL024216.

_ , and W. D. Hibler III, 1997: On an efficient numerical method for modeling sea ice dynamics. J. Geophys. Res., 102, 8691-8702.

- and D. A. Rothrock, 2001: A thickness and enthalpy distribution sea-ice model. J. Phys. Oceanogr., 31, 2986-3001.

_ and _ 2003: Modeling global sea ice with a thickness and enthalpy distribution model in generalized curvilinear coordinates. Mon. Wea. Rev., 131, 681-697.

- , and 2005: The effect of sea-ice rheology in numerical investigations of climate. J. Geophys. Res., 110, C08014, doi:10.1029/2004JC002599.

— R. Rindsay, M. Steele, and A. Schweiger, 2008: What drove the dramatic retreat of Arctic sea ice during summer 2007? Geophys. Res. Lett., 35, L11505, doi:10.1029/2008GL034005. 